\title{
Optimasi Formula Basis Sediaan Edible Film dengan Kombinasi Polimer Carbomer 940 dan Kappa Karagenan
}

\author{
Patihul Husni*, Wirna Grace Tua Sihombing, Taofik Rusdiana \\ Departemen Farmasetika dan Teknologi Farmasi, Fakultas Farmasi, Universitas Padjadjaran \\ *E-mail: patihul.husni@unpad.ac.id \\ (Submit 16/5/2020, Revisi 26/5/2020, Diterima 27/5/2020)
}

\begin{abstract}
Abstrak
Salah satu bentuk sediaan mukoadhesif adalah edible film. Bentuk ini dapat meningkatkan waktu tinggal pada mukosa dibandingkan dengan gel oral. Pada penghantaran lokal untuk penyakit mulut seperti sariawan, edible film membantu melindungi luka permukaan sehingga rasa sakit dapat berkurang serta pengobatan lebih efektif. Tujuan penelitian ini adalah optimasi formula basis sediaan edible film menggunakan kombinasi Carbomer 940 dan kappa karagenan dengan merancang beberapa formula secara bertahap sampai didapatkan komposisi formula yang baik. Metode pembuatan sediaan edible film yang digunakan dalam penelitian ini adalah solvent casting yang evaluasinya berupa kemampuan formula membentuk lembaran sediaan edible film yang kering, tidak lengket dan tidak mudah sobek. Hasil optimasi menunjukkan bahwa basis sediaan edible film menggunakan kombinasi Carbomer 940 dan kappa karagenan menghasilkan sediaan edible film yang baik yaitu formula dengan konsentrasi karagenan sebesar 1,5\% dan Carbomer 940 antara 0,1-0,5\%. Berdasarkan hal tersebut dapat disimpulkan bahwa formula dengan kombinasi Carbomer 940 1,5\% dan kappa karagenan $0,1-0,5 \%$ dapat digunakan sebagai basis sediaan edible film.
\end{abstract}

Kata kunci: Mukoadhesif, Edible Film, Polimer, Carbomer, Kappa karagenan

\section{Outline}

- Pendahuluan

- Metode

- Hasil dan Pembahasan

- Kesimpulan

- Daftar Pustaka

\section{Pendahuluan}

Mukoadhesif merupakan konsep baru yang diperkenalkan dalam hal peningkatan pelepasan obat, target obat dan penyerapan obat. Elemen kunci dari sistem untuk desain dari polimer mukoadhesif yaitu kemampuan untuk melekat pada lapisan mukosa ${ }^{1-3}$. Sistem penghantaran obat melalui rute mukosa oral tidak melewati first pass effect metabolism dan zat aktif tidak melewati cairan asam lambung sehingga terhindar dari kondisi yang ekstrem ${ }^{4}$. 
Apabila dibandingkan dengan sistem penghantaran obat melalui rute nasal dan rektal, daerah ini rendah akan proses enzimatis dan proses inaktivasi zat aktif karena proses degradasi secara biokimia dapat dikurangi $i^{5-8}$.

Edible film merupakan salah satu contoh sediaan mukoadhesif. Edible film lebih disukai oleh pasien dalam hal kenyamanan dan fleksibilitas dibandingkan dengan tablet. Edible film juga dapat meningkatkan waktu tinggal pada mukosa dibandingkan dengan gel oral. Gel oral relatif mudah terhapus dan terbawa oleh air liur. Dalam kasus penghantaran lokal untuk penyakit mulut, edibe film juga membantu melindungi luka permukaan, sehingga rasa sakit dapat berkurang serta mengobati penyakit lebih efektif ${ }^{9-13}$.

Karakter yang khas dari sediaan edible film yaitu berupa film tipis yang bagus, tidak mengganjal di lidah, daya mukoadhesifnya baik, cepat hancur, dan melepaskan zat berkhasiat, serta tersedia dalam berbagai bentuk dan ukuran ${ }^{14}$. Dari sisi ekonomisnya, edible film lebih praktis untuk dibawa, kecil, tipis, ringan, stabil dalam penyimpanan dan transportasi serta lebih mudah dikonsumsi dibandingkan dengan tablet dan sirup ${ }^{15}$.

Salah satu komponen dalam sediaan edible film adalah polimer yang dapat membentuk lapisan film. Kappa karagenan dapat digunakan untuk tujuan ini ${ }^{16}$. Polimer bersifat mukoadhesif dapat digunakan dalam sediaan edible film untuk memberikan efek adhesif terhadap mukosa ${ }^{17}$. Bahan bersifat mukoadhesif umumnya berupa polimer baik bahan natural seperti karagenan, semisintetik, atau sintetik seperti Carbomer ${ }^{18}$. Untuk mendapatkan sediaan edible film yang baik dan memenuhi persyaratan, perlu dilakukan optimasi formula menggunakan kombinasi polimer.

\section{Metode}

Penelitian ini menggunakan metode eksperimental di laboratorium meliputi pengumpulan bahan dan optimasi formula edible film.

\section{Pengumpulan bahan}

Bahan-bahan yang digunakan adalah Carbomer 940 (Quadrant), pati jagung (Quadrant), gliserin (Quadrant), natrium benzoat (Quadrant), sukralos (Quadrant), kappa karagenan (Quadrant), dan aquadest yang diperoleh dari Laboratorium Farmasetika dan Laboratorium Teknologi Farmasi, Fakultas Farmasi, Universitas Padjadjaran.

\section{Optimasi formula}

Optimasi formula basis sediaan edible film dilakukan dengan merancang beberapa formula secara bertahap hingga didapatkan formula yang baik dan akan digunakan sebagai basis sediaan edible film. Rancangan optimasi formula sediaan edible film tertera pada tabel-tabel di bawah ini. 
Tabel 1. Formula Optimasi Edible film I

\begin{tabular}{|l|c|c|}
\hline \multirow{2}{*}{\multicolumn{1}{c|}{ Bahan }} & \multicolumn{3}{|c|}{ Formula (\%b/v) } \\
\hline Carbomer 940 & FIA & FIB \\
\hline Pati Jagung & 0,1 & 0,5 \\
\hline Gliserin & 2 & 2 \\
\hline Natrium Benzoat & 2 & 2 \\
\hline Sukralos & 0,1 & 0,1 \\
\hline Aquadest ad (mL) & 0,1 & 0,1 \\
\hline
\end{tabular}

Tabel 3. Formula Optimasi Edible film III

\begin{tabular}{|l|c|c|}
\hline \multirow{2}{*}{\multicolumn{1}{c|}{ Bahan }} & \multicolumn{2}{|c|}{ Formula (\%b/v) } \\
\hline Kappa karagenan & FIIIA & FIIIB \\
\hline Gliserin & 0,8 & 1 \\
\hline Natrium Benzoat & 2 & 2 \\
\hline Sukralos & 0,1 & 0,1 \\
\hline Aquadest ad $(\mathrm{mL})$ & 0,1 & 0,1 \\
\hline
\end{tabular}

Tabel 2. Formula Optimasi Edible film II

\begin{tabular}{|l|c|c|}
\hline \multicolumn{1}{|c|}{ Bahan } & \multicolumn{3}{|c|}{ Formula $(\% \mathrm{~b} / \mathrm{v})$} \\
\hline Carbomer 940 & FIIA & FIIB \\
\hline Kappa karagenan (mL) & 0,2 & 0,2 \\
\hline Gliserin & 0,2 & 0,4 \\
\hline Natrium Benzoat & 2 & 2 \\
\hline Sukralos & 0,1 & 0,1 \\
\hline Aquadest ad (mL) & 0,1 & 0,1 \\
\hline
\end{tabular}

Tabel 4. Formula Optimasi Edible film IV

\begin{tabular}{|l|c|c|}
\hline \multirow{2}{*}{ Bahan } & \multicolumn{2}{|c|}{ Formula (\%b/v) } \\
\hline Kappa karagenan & FIVA & FIVB \\
\hline Gliserin & 1,5 & 2 \\
\hline Natrium Benzoat & 2 & 2 \\
\hline Sukralos & 0,1 & 0,1 \\
\hline Aquadest ad (mL) & 0,1 & 0,1 \\
\hline
\end{tabular}

Tabel 5. Formula Optimasi Edible film $V$

\begin{tabular}{|l|c|c|c|c|c|c|}
\hline \multicolumn{1}{|c|}{ Bahan } & \multicolumn{7}{|c|}{ Formula $(\% \mathbf{b} / \mathbf{v})$} \\
\hline Kappa karagenan & FVA & FVB & FVC & FVD & FVE & FVF \\
\hline Carbomer 940 & 1,5 & 1,5 & 1,5 & 1,5 & 1,5 & 1,5 \\
\hline Gliserin & 0,1 & 0,15 & 0,2 & 0,3 & 0,4 & 0,5 \\
\hline Natrium benzoat & 2 & 2 & 2 & 2 & 2 & 2 \\
\hline Sukralos & 0,1 & 0,1 & 0,1 & 0,1 & 0,1 & 0,1 \\
\hline Aquadest ad (mL) & 0,03 & 0,03 & 0,03 & 0,03 & 0,03 & 0,03 \\
\hline
\end{tabular}

\section{Prosedur pembuatan}

Edibel film dibuat dengan beberapa tahapan yaitu Carbomer 940 didispersikan dalam $50 \mathrm{ml}$ aquadest kemudian dipanaskan dan diaduk terus-menerus pada suhu $\pm 90{ }^{\circ} \mathrm{C}(\mathrm{A})$. Kappa karagenan (atau pati jagung) dimasukkan dalam larutan A sambil diaduk (B). Sukralos dan Natrium Benzoat dilarutkan dalam air panas $\left(70-80{ }^{\circ} \mathrm{C}\right)$, kemudian ditambahkan ke dalam campuran B. Gliserin ditambahkan ke dalam campuran B. Sisa aquadest ditambahkan ke dalam campuran B dan diaduk homogen. Campuran akhir dituangkan dan diratakan pada cetakan $(20 \mathrm{~cm}$ x $15 \mathrm{~cm})$. Pengeringan dilakukan di dalam oven pada suhu 50-60 ${ }^{\circ} \mathrm{C}$ selama 24 jam, lalu dilepaskan dari cetakan dan dipotong-potong dengan ukuran $3 \times 2 \mathrm{~cm}$. Sebagai catatan, formula optimasi III dan IV (Tabel 3 dan 4) tidak menggunakan Carbomer 940 dalam pembuatannya.

\section{Hasil dan Pembahasan}

Optimasi formula dilakukan untuk mengetahui konsentrasi polimer yang akan digunakan untuk mendapatkan formula yang baik. Proses pembuatan edible film dilakukan dengan metode solvent casting. 
Pada proses optimasi ini, evaluasi yang dilakukan hanya tekstur yang berupa kemampuan formula membentuk lembaran sediaan edible film yang kering, tidak lengket dan tidak mudah sobek karena merupakan tahap awal pengembangan formula basis sediaan edible film. Pada optimasi pertama (Tabel 1), edible film tidak terbentuk dan hanya terbentuk lapisan tipis, agak basah dan lengket pada cetakan. Hal ini terjadi karena Carbomer 940 bersifat higroskopis ${ }^{19}$ sehingga diperlukan kombinasi polimer Carbomer 940 dengan polimer lainnya agar dapat membentuk film yang lebih baik. Selain itu, pati jagung tidak dapat larut sehingga pada cetakan terlihat serbuk pati jagung yang mengendap.

Hasil optimasi kedua (Tabel 2) menunjukkan bahwa sediaan edible film dapat terbentuk dan dapat dilepaskan dari cetakan. Namun setelah dilepaskan dari cetakan, edible film yang terbentuk langsung menempel dengan sisi edible film lain dan tidak dapat dipisahkan kembali. Edible film yang terbentuk juga terlalu tipis dan sangat mudah sobek.

Polimer yang digunakan untuk optimasi edible film yang ketiga (Tabel 3) adalah karagenan tanpa Carbomer 940. Edible film terbentuk dengan menggunakan kedua formula. Hasil dari FIIIA terbentuk edible film, namun agak lengket dan agak mudah sobek karena edible film yang terbentuk terlalu tipis. Hasil dari FIIIB terbentuk edible film agak sedikit lengket dan tidak mudah sobek. Edible film FIIIB lebih baik dibanding dengan FIIIA. Akan tetapi, penambahan jumlah polimer kappa karagenan diperlukan untuk menghasilkan edible film yang lebih tebal sehingga tidak mudah sobek.

Formula optimasi pada Tabel 4 menghasilkan sediaan edible film yang tidak lengket, tidak mudah sobek dan lebih elastis. Hasil edible film lebih baik dibanding dengan dua formula sebelumnya. Optimasi ketiga dan keempat dilakukan untuk mengetahui jumlah kappa karagenan yang diperlukan untuk menghasilkan edible film yang baik. Jumlah kappa karagenan yang digunakan untuk optimasi selanjutnya adalah $1,5 \%$. Berdasarkan beberapa percobaan yang telah dilakukan, konsentrasi dibawah 1,5\% membentuk edible film yang lebih mudah sobek pada saat dilepaskan dari cetakan, sedangkan konsentrasi diatas $1,5 \%$ hasilnya sangat kaku dan butuh waktu pengeringan yang lebih lama.

Pada optimasi kelima (Tabel 5), edible film terbentuk menggunakan kombinasi kappa karagenan dan carbomer 940 (Gambar 1). Jumlah kappa karagenan yang digunakan sejumlah $1,5 \%$ sesuai dengan hasil optimasi yang sebelumnya. Carbomer 940 digunakan dengan variasi konsentrasi untuk melihat apakah edible film yang terbentuk baik jika dilakukan kombinasi polimer dan untuk mengetahui jumlah carbomer 940 yang diperlukan agar menghasilkan edible film yang baik bila dikombinasikan dengan kappa karagenan.

Penggunaan carbomer 940 pada formula ini sebagai polimer mukoadhesif ${ }^{17}$. Penelitian lebih lanjut harus dilakukan untuk mengevaluasi sifat mukoadhesif dari sediaan edible film yang dihasilkan. 


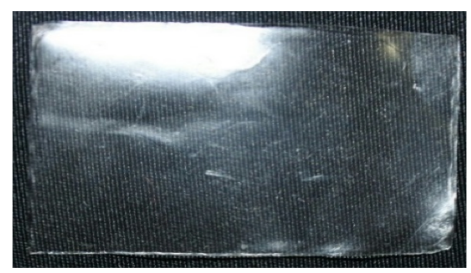

Gambar 1. Sediaan edible film

Formula dengan menggunakan variasi Carbomer 940 tanpa kombinasi dengan polimer lain dapat membentuk gel saja namun tidak dapat membentuk lapisan film yang kering. Hasil yang terbentuk hanya berupa lapisan tipis dan agak basah, lapisan tersebut juga tidak bisa dilepaskan dari cetakan karena sangat lengket dan basah. Hal ini terjadi karena Carbomer 940 bersifat higroskopis ${ }^{19}$, sehingga harus dilakukan kombinasi dengan polimer lain. Polimer yang digunakan yaitu kappa karagenan. Lapisan film dapat terbentuk saat dilakukan kombinasi antara Carbomer 940 dengan kappa karagenan. Karagenan yang digunakan adalah kappa karagenan (k-Carrageenan). Kappa karagenan digunakan karena dapat membentuk gel yang lembut dan fleksibel dibandingkan dengan karagenan jenis lainnya ${ }^{19,}{ }^{20}$. Kappa karagenan juga telah digunakan dalam pembuatan edible film ${ }^{21}$.

Variasi konsentrasi Carbomer 940 yaitu antara 0,1-0,5\%. Carbomer dengan konsentrasi $0,5-2 \%$ dapat digunakan sebagai pembentuk gel ${ }^{19}$. Namun apabila terbentuk gel akan sulit dilakukan penuangan saat pencetakan film, sehingga digunakan konsentrasi yang lebih rendah. Berdasarkan beberapa percobaan yang telah dilakukan, konsentrasi diatas $0,5 \%$ membentuk gel yang mempersulit penuangan pada cetakan.

\section{Kesimpulan}

Kombinasi Carbomer 940 dan kappa karagenan menghasilkan sediaan edible film yang baik. Berdasarkan hasil evaluasi tekstur sediaan edible film yang dihasilkan, formula dengan kombinasi Carbomer 940 sebesar 1,5\% dan kappa karagenan antara 0,1-0,5\% dapat membentuk basis sediaan edible film.

\section{Daftar Pustaka}

1. Boddupalli BM, Mohammed ZN, Nath RA, Banji D. Mucoadhesive Drug Delivery System: An Overview. J Adv Pharm Technol Res. 2010;1(4):381.

2. Bhati R, Nagrajan RK. A Detailed Review on Oral Mucosal Drug Delivery System. International Journal of Pharmaceutical Sciences and Research. 2012;3(3):659.

3. Patil S, Murthy R, Mahajan H, Wagh R, Gattani S. Mucoadhesive Polymers: Means of Improving Drug Delivery. Pharma Times 2006;38(4):25-8.

4. Huanbutta K, Sangnim T. Bioadhesive Films for Drug Delivery Systems. 2020:101.

5. Zhang $\mathrm{H}$, Zhang J, Streisand JB. Oral Mucosal Drug Delivery. Clinical Pharmacokinetics. 2002;41(9):661-80. 
6. Hooda R, Tripathi M, Kapoor K. A Review on Oral Mucosal Drug Delivery System. The Pharma Innovation. 2012;1(1, Part A):14.

7. Russo E, Selmin F, Baldassari S, Gennari CGM, Caviglioli G, Cilurzo F, et al. A Focus on Mucoadhesive Polymers and Their Application an Buccal Dosage Forms. Journal of Drug Delivery Science and Technology. 2016;32:113-25.

8. Bruschi ML, de Freitas O. Oral Bioadhesive Drug Delivery Systems. Drug Development and Industrial Pharmacy. 2005;31(3):293-310.

9. Thakur N, Bansal M, Sharma N, Yadav G, Khare P. Overview "A Novel Approach of Fast Dissolving Films and Their Patients". Advances in Biological Research. 2013;7(2):50-8.

10. Sari DI, Fitriana M, Mulyadi RR, Hidayati L, editors. Karakteristik dan Uji Stabilitas Fisik Sediaan Edible Film Ekstrak Etanol Kulit Batang Kasturi (Mangifera Casturi Kosterm) Berbasis Gelatin. Prosiding Seminar Nasional Dan Presentasi IImiah Perkembangan Terapi Obat Herbal Pada Penyakit Degeneratif; 2017.

11. Morales JO, McConville JT. Manufacture and Characterization of Mucoadhesive Buccal Films. European Journal of Pharmaceutics and Biopharmaceutics. 2011;77(2):187-99.

12. Nagar P, Chauhan I, Yasir M. Insights into Polymers: Film Formers in Mouth Dissolving Films. Drug Invention Today 2011;3(12).

13. Bala R, Pawar P, Khanna S, Arora S. Orally Dissolving Strips: A New Approach To Oral Drug Delivery System. Int J Pharm Investig. 2013;3(2):67.

14. Saini S, Nanda A, Hooda M, Komal. Fast Dissolvig Films (Fdf) : Innovative Drug Delivery System. Pharmacologyonline. 2011;2:919-28.

15. Harmely F, Deviarny C, Yenni WS. Formulasi dan Evaluasi Sediaan Edible Film Dari Ekstrak Daun Kemangi (Ocimum Americanum L.) Sebagai Penyegar Mulut. Jurnal Sains Farmasi \& Klinis. 2014;1(1):38-47.

16. Zhang Y-b, Jiang J. Preparation and Performance Characterization of Soy Protein Isolate Edible Film J Food Science. 2012;6.

17. Singla AK, Chawla M, Singh A. Potential Applications of Carbomer in Oral Mucoadhesive Controlled Drug Delivery System: A Review. Drug Development and Industrial Pharmacy. 2000;26(9):913-24.

18. Garg V, Jindal S. Buccal Bioadhesive Drug Delivery Systems and Their Applications. 2020:213.

19. Rowe R, Sheskey P, Quinn M. Handbook of Pharmaceutical Excipients. 6th ed: Pharmaceutical Press 2009. 
20. Necas J, Bartosikova L. Carrageenan: A Review. Veterinarni Medicina. 2013;58(4).

21. Febianti M, Ghozali AA, Redjeki S, Iriani I. Edible Film dari Tepung Kappa Karagenan dan Kitosan Cangkang Rajungan dengan Gliserol. Journal of Chemical and Process Engineering. 2020;1(01):16-21. 